
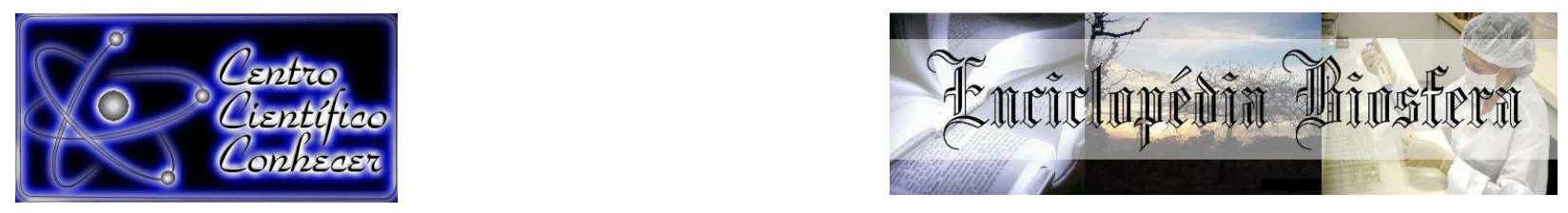

\title{
ESTABILIDADE DE AGREGADOS EM SOLO CULTIVADO COM CAPIM-TIFTON 85 SOB IRRIGAÇÃO E FORMAS DE SUPRIMENTO DE NITROGÊNIO
}

\footnotetext{
Marina Luciana Abreu de Melo', Aline Martineli Batista ${ }^{2}$, Gabriela Soares Santos Araújo $^{3}$, Bruno Montoani Silva ${ }^{4}$; Maria Celuta Machado Viana ${ }^{5}$

${ }^{1}$ Graduanda de Engenharia Agronômica da Universidade Federal de São João del-Rei / Bolsista CNPq (marinaluciana94@gmail.com) Minas Gerais - Brasil

${ }^{2}$ Mestranda em Solos e Nutrição de Plantas da Escola Superior de Agricultura Luiz de Queiroz/Universidade de São Paulo (ESALQ/USP)

${ }^{3}$ Graduanda de Engenharia Agronômica da Universidade Federal de São João delRei / Bolsista FAPEMIG

${ }^{4}$ Professor Doutor do Departamento de Ciência do Solo da Universidade Federal de Lavras

${ }^{5}$ Doutora em Fisiologia Vegetal e Bolsista de Produtividade FAPEMIG na Empresa de Pesquisa Agropecuária de Minas Gerais (EPAMIG)
}

\section{Recebido em: 08/04/2017 - Aprovado em: 10/06/2017 - Publicado em: 20/06/2017 DOI: 10.18677/EnciBio_2017A48}

Dentre as diferentes estratégias de recuperação da qualidade estrutural do solo, destaca-se o uso de capim-tifton 85 (Cynodon sp.), o qual apresenta um sistema radicular denso, associado à fertilização orgânica. $O$ objetivo deste trabalho foi avaliar a estabilidade da estrutura do solo em área de pastejo rotacionado de capimtifton 85, em função da aplicação de adubo orgânico e irrigação, a fim de investigar se há incremento na qualidade física do solo. Os tratamentos consistiram em diferentes formas de suprimento de $\mathrm{N}$, testadas em ambiente irrigado e de sequeiro em Prudente de Morais (MG): $400 \mathrm{~kg} / \mathrm{ha}$ de ureia (T1); $400 \mathrm{~kg} / \mathrm{ha}$ de esterco bovino (T2); $400 \mathrm{Kg} / \mathrm{ha}$ de ureia e esterco, na proporção 1:1 (T3) e a testemunha, sem adubação nitrogenada (T4). Determinaram-se os seguintes atributos de agregação do solo nas camadas 0-5 e 5-10 cm: diâmetro médio ponderado (DMP), diâmetro médio geométrico (DMG), índice de estabilidade de agregados da classe $<0,25 \mathrm{~mm}$ (IEA) e índice de floculação do solo (IF). Realizou-se análise granulométrica e de carbono orgânico nas mesmas camadas. As variáveis DMP, DMG e IEA não se diferirem entre os tratamentos, mas foram superiores com o uso de irrigação; a forma de suprimento de $\mathrm{N}$ para adubação de capim-tifton 85 foi pouco determinante para a estabilidade da estrutura do solo no tempo avaliado, porém o uso da irrigação favorece atributos de agregação.

PALAVRAS-CHAVE: adubação, estrutura do solo, irrigação de Cynodon sp. 


\title{
STABILITY OF AGGREGATES IN SOIL CULTIVATED WITH TIFTON 85 GRASS UNDER IRRIGATION AND FORMS OF NITROGEN SUPPLY
}

\begin{abstract}
Among the different strategies for recovering soil structural quality, we highlight the use of Tifton 85 grass (Cynodon sp.), which has a dense root system associated with organic fertilization. The aim of this work was to evaluate the stability of the soil structure in rotational grazing area of Tifton 85, as a function of the application of organic fertilizer and irrigation, in order to investigate if there is an increase in the soil physical quality. The treatments consisted in different forms of $\mathrm{N}$ supply, tested in irrigated and dry environment in Prudente de Morais (MG): $400 \mathrm{Kg} / \mathrm{ha}$ of urea (T1); $400 \mathrm{Kg} / \mathrm{ha}$ of bovine manure (T2); $400 \mathrm{Kg} / \mathrm{ha}$ of urea and manure, in the proportion 1:1 (T3) and the control, without nitrogen fertilization (T4). The following soil aggregation attributes were determined in layers $0-5$ and 5-10 cm: mean weightdiameter (MWD), geometric mean diameter (GMD), stability index of aggregates of class $<0,25 \mathrm{~mm}$ (SIA) and flocculation index (IF). Granulometric and organic carbon analysis were performed on the same layers. MWD, GMD and SIA did not differ among treatments, but were higher with irrigation use. For IF there was no statistical difference. The $\mathrm{N}$ form for fertilization of Tifton 85 grass was little determinant to soil structure stability in the evaluated time, but irrigation use favors aggregation attributes.
\end{abstract}

KEYWORDS: soil structure, organic fertilization, Cynodon sp irrigation.

\section{INTRODUÇÃO}

A atividade pecuária no Brasil apresentou uma ampla expansão na década de 1970, notadamente na região do Cerrado, que se tornou a região mais importante de produção de carne bovina no país (EMBRAPA, 2002; PERON \& EVANGELISTA, 2004). A maior parcela dessa produção é resultante de sistemas de criação extensivos, sendo que as pastagens se destacam como principal fonte alimentar. Entretanto, a degradação das pastagens tem sido um entrave para o aumento de produtividade, além de afetar a sustentabilidade da produção pecuária.

A degradação de pastagens pode ser ocasionada por diversos fatores, como escolha incorreta da forrageira, adubação ineficiente e manejo inadequado (PERON \& EVANGELISTA, 2004). Esses fatores implicam em perda da qualidade física, química e biológica do solo, o que intensifica o processo de degradação, acarretando danos ambientais e perdas financeiras aos produtores. Nesse contexto, evidencia-se a importância do desenvolvimento de estratégias que visem ao aumento da eficiência dos sistemas produtivos, com destaque para o manejo adequado do solo sob as áreas de pastagem no Brasil.

$\mathrm{Na}$ literatura, são encontrados diversos estudos sobre propriedades físicas de solos cultivados com espécies forrageiras (RESENDE et al., 2012; SANTOS et al., 2012; ORTIGARA et al., 2014; FIDALSKI et al., 2013; BORGES et al., 2015; FIDALSKI, 2015). Dentre essas espécies, as gramíneas se sobressaem por possuírem um sistema radicular robusto e rapidamente renovado, como as espécies do gênero Cynodon, a qual pertence o capim-tifton 85. Essa forrageira originou-se a partir do cruzamento entre o capim-tifton $68 \mathrm{com}$ a espécie Bermuda Grass da África do Sul e é apontada, por alguns autores, como uma alternativa para a reestruturação de solos fisicamente degradados (WENDLING et al., 2005; SEVERIANO et al., 2010; LIMA et al., 2012; BASSO et al., 2014; COLUSSI et al., 2014). 
A escolha adequada da espécie forrageira pode ser aliada a outras ferramentas de manejo que incrementem a qualidade e a produtividade das pastagens, como a adubação de cobertura e o uso de irrigação. A fertilização do solo constitui uma prática que estimula o crescimento da planta, com efeitos positivos na estrutura do solo (LIMA et al., 2012).

Em relação às pastagens irrigadas, SANCHES et al. (2015) afirmam que áreas de capim-tifton 85 irrigadas têm demostrado aumentos relevantes de produtividade, o que também pode favorecer a qualidade física do solo. Além disso, o processo de agregação das partículas do solo é afetado pelos seus ciclos naturais de umedecimento e secagem, os quais são afetados pelo uso da irrigação.

Segundo OLIVEIRA et al. (2015), a adição de compostos orgânicos ao solo promove melhoria de sua qualidade estrutural. Esse benefício pode ser evidenciado pelo uso de indicadores de agregação da fração sólida do solo, uma vez que o incremento de matéria orgânica é relacionado ao aumento na estabilidade de agregados (CALONEGO \& ROSOLEM, 2008). Entre esses indicadores, o diâmetro médio ponderado, o diâmetro médio geométrico e o índice de estabilidade de agregados com diâmetro inferior a $0,25 \mathrm{~mm}$ são alguns dos parâmetros mais empregados para a avaliação do nível de agregação e estabilidade da estrutura do solo (CASTRO FILHO et al., 1998; WENDLING et al., 2005; SILVA et al., 2014).

Cada um desses parâmetros reflete um aspecto diferente da qualidade física do solo: o valor de DMP está diretamente relacionado à porcentagem de agregados com diâmetro superior a $0,25 \mathrm{~mm}$ (macroagregados), enquanto o DMG constitui uma estimativa do diâmetro de agregados predominante. O IEA, por sua vez, aponta a condição de agregação total do solo (CASTRO FILHO et al., 1998). O índice de floculação da argila também pode ser utilizado como indicador, uma vez que permite inferir se há condições necessárias para ocorrer o processo de agregação no solo.

Sabendo-se que as gramíneas do gênero Cynodon apresentam rápida resposta a estímulos químicos, o objetivo deste trabalho foi avaliar a estabilidade da estrutura do solo em área de pastejo rotacionado de capim-tifton 85 , com uso de adubação orgânica e irrigação.

\section{MATERIAL E MÉTODOS}

Este estudo foi realizado no município de Prudente de Morais - MG, localizado sob a latitude 19 $28^{\prime}$ '29" S, longitude 44 09' 34" W e altitude média de $759 \mathrm{~m}$ (MAPCOORDINATES, 2016). A área de experimento, com aproximadamente 1,8 ha, pertence à Fazenda Experimental de Santa Rita da Empresa de Pesquisa Agropecuária de Minas Gerais, regional Centro-Oeste (EPAMIG/CTCO). O clima da região é tipo Cwa, segundo classificação de Köppen-Geiger, com temperatura média de 21,8ํㅡ $\mathrm{C}$ e precipitação anual de $1.329 \mathrm{~mm}$ (IBGE, 2013). O solo foi classificado como Latossolo Vermelho distrófico (LVd) (EMBRAPA, 2013).

As amostras de solo foram coletadas em uma pastagem de capim-tifton 85, subdividida em 24 piquetes de $18 \times 40 \mathrm{~m}$ para pastejo rotacionado. A implantação do experimento ocorreu em janeiro de 2011, com o uso de grade aradora e niveladora para o preparo do solo. Nessa ocasião, também foi realizada a abertura de sulcos para o plantio manual da gramínea. Foram aplicadas 02 toneladas de calcário dolomítico para fins de correção do solo e a adubação de plantio, aplicada a lanço, empregou $578 \mathrm{Kg}$ de adubo 08:28:16 + FTE e $650 \mathrm{Kg}$ de adubo 20:00:20.

O plantio do pasto ocorreu em março de 2011, com renovação em outubro do mesmo ano. A área foi utilizada para pastejo de bovinos por aproximadamente dois anos, com a entrada de animais durante o período de agosto de 2012 a abril de 
2014, com uma média de 50 vacas adultas e bezerros por entrada. Após esse período, a pastagem foi mantida em repouso por cerca de um ano até a data das amostragens, em setembro de 2015.

Foram avaliados 16 piquetes em delineamento em blocos casualizados (DBC), com 4 repetições. O esquema fatorial foi $2 \times 4$, testando-se os seguintes fatores: uso de irrigação e forma de adubação nitrogenada. Os tratamentos foram: $400 \mathrm{Kg} / \mathrm{ha}$, de $\mathrm{N}$ na forma mineral via ureia (T1); $400 \mathrm{Kg} / \mathrm{ha}$ de N, na forma orgânica via esterco de bovino (T2); $400 \mathrm{Kg} / \mathrm{ha}$ de N, 50\% na forma mineral e $50 \%$ na forma orgânica, com o uso das mesmas fontes (T3) e a testemunha, sem suprimento de $\mathrm{N}$ (T4). Houve parcelamento da adubação com quatro aplicações a lanço de 30, 25, 20 e $10 \%$ da dose total. Os tratamentos foram replicados em dois ambientes, um irrigado por aspersão em malha fixa e outro de sequeiro, sendo a primeira irrigação realizada em janeiro de 2012 e, a última, em setembro de 2013, de acordo com o ciclo fenológico da forrageira.

A estabilidade da estrutura do solo foi examinada por meio da coleta de agregados nas camadas 0-5 e 5-10 cm. Após secagem ao ar, as amostras foram destorroadas, passadas em peneira de $8 \mathrm{~mm}$ e retidas em peneira de $4 \mathrm{~mm}$. Para cada repetição, foram pesados $25 \mathrm{~g}$ de agregados, os quais foram saturados por ascensão capilar e submetidos ao tamisamento úmido com oscilação vertical por 15 min, em agitador do tipo Yoder, equipado com 2 conjuntos de peneiras com malha de 2,00; 1,00; 0,50; 0,25 e 0,09 mm (EMBRAPA, 2011). Em seguida, os agregados restantes em cada malha foram transferidos para recipientes metálicos e conduzidos à estufa de secagem a $105^{\circ} \mathrm{C}$, durante 24 horas. A quantificação do conteúdo retido em cada peneira permitiu a determinação da porcentagem de agregados por classes de diâmetro, associadas às aberturas das malhas. Foram calculados os índices diâmetro médio ponderado (DMP), diâmetro médio geométrico (DMG) e índice de estabilidade de agregados da classe $<0,25 \mathrm{~mm}$ (IEA), conforme as expressões descritas por CASTRO FILHO et al. (1998):

$$
\mathrm{DMP}=\sum_{j=1}^{n}(\mathrm{xi} \cdot \text { wi) }
$$

em que $\mathbf{w i}=$ proporção de cada classe em relação ao total; $x i$ = diâmetro médio das classes $(\mathrm{mm})$;

$$
D M G=\frac{\sum_{l=1}^{n} w p \cdot \log x i}{\sum_{i=1}^{n} x i}
$$

em que wp = peso dos agregados de cada classe $(g)$;

$$
\text { IEA }=\left(\frac{\text { Peso da amostra seca }- \text { wp25 - areia }}{\text { Peso da amostra seca-areia }}\right) 100
$$

em que wp25 = peso dos agregados da classe $<0,25 \mathrm{~mm}(\mathrm{~g})$.

O índice de floculação do solo (IF) foi calculado por meio da determinação da argila dispersa em água (ADA). As amostras foram secas ao ar e passadas em peneira com malha de $2 \mathrm{~mm}$, obtendo-se a terra fina seca ao ar (TFSA). A análise foi executada pelo método da pipeta, empregando-se $10 \mathrm{~g}$ de solo e agitação lenta em agitador mecânico do tipo Wagner a 40 rpm, por 16 horas, sem a utilização de dispersantes químicos. Para o cálculo de IF, foi aplicada a seguinte equação expressa em EMBRAPA (2011): 


$$
\mathrm{IF}=((\mathrm{AT}-\mathrm{ADA}) / \mathrm{AT}) 100
$$

em que: IF= índice de floculação (\%); $A T=$ argila total $(\mathrm{g} / \mathrm{kg}) ; A D A=$ argila dispersa em água $(\mathrm{g} / \mathrm{kg})$.

Para a caracterização do solo, foram realizadas a análise granulométrica e a determinação do teor de carbono orgânico $(\mathrm{C})$. A porcentagem de matéria orgânica do solo (MOS) foi obtida pela multiplicação de C pelo fator de Van Bemmelen, de acordo com a equação:

$$
\text { MOS }=1,724 \mathrm{C}
$$

em que: MOS = matéria orgânica do solo $(\mathrm{g} / \mathrm{Kg}) ; \mathrm{C}=$ carbono orgânico $(\mathrm{g} / \mathrm{Kg})$; 1,724 = fator de Van Bemmelen. Os resultados da análise granulométrica e da porcentagem de MOS são apresentados na Tabela 1.

TABELA 1 - Teores das frações areia, silte, argila e porcentagem de matéria orgânica no solo (MOS) de um LVd nas camadas $0-5$ e $5-10 \mathrm{~cm}$.

\begin{tabular}{ccccc}
\hline \multirow{2}{*}{ Tratamentos } & Areia & Silte & Argila & MOS \\
& - & Camada 0-5 cm \\
T1 & 21,41 & 18,24 & 60,35 & 4,76 \\
T2 & 23,77 & 16,98 & 59,25 & 5,23 \\
T3 & 24,54 & 16,47 & 58,99 & 5,28 \\
T4 & 22,38 & 19,06 & 58,56 & 4,29 \\
T1 & 21,65 & Camada 5-10 cm & \\
T2 & 22,12 & 17,79 & 60,56 & 4,43 \\
T3 & 22,36 & 15,66 & 59,99 & 4,49 \\
T4 & 21,73 & 16,95 & 61,98 & 4,18 \\
\hline
\end{tabular}

Análise granulométrica: método da pipeta e solução dispersante de $\mathrm{NaOH} 1,0$ M. Porcentagem de MOS: método Walkley-Black (WALKLEY \& BLACK, 1934).

O procedimento estatístico correspondeu à análise de variância a $5 \%$ de significância. Quando significativo, foi aplicado o teste de médias Skott-Knott também a $5 \%$ de significância, com auxílio da linguagem $R$ pacote ExpDes (FERREIRA et al., 2014).

\section{RESULTADOS E DISCUSSÃO}

A distribuição percentual de agregados por classes de diâmetro evidenciou ausência de diferença significativa entre as formas de suprimento de $\mathrm{N}$, em ambas as profundidades, como pode ser constatado pelas Figuras 1 e 2 . Ainda conforme essas figuras, para todos os tratamentos, nas duas camadas, mais de $85 \%$ dos agregados ficaram retidos na malha de maior abertura $(2,00 \mathrm{~mm})$, o que indica elevado grau de estabilidade da estrutura do solo. 


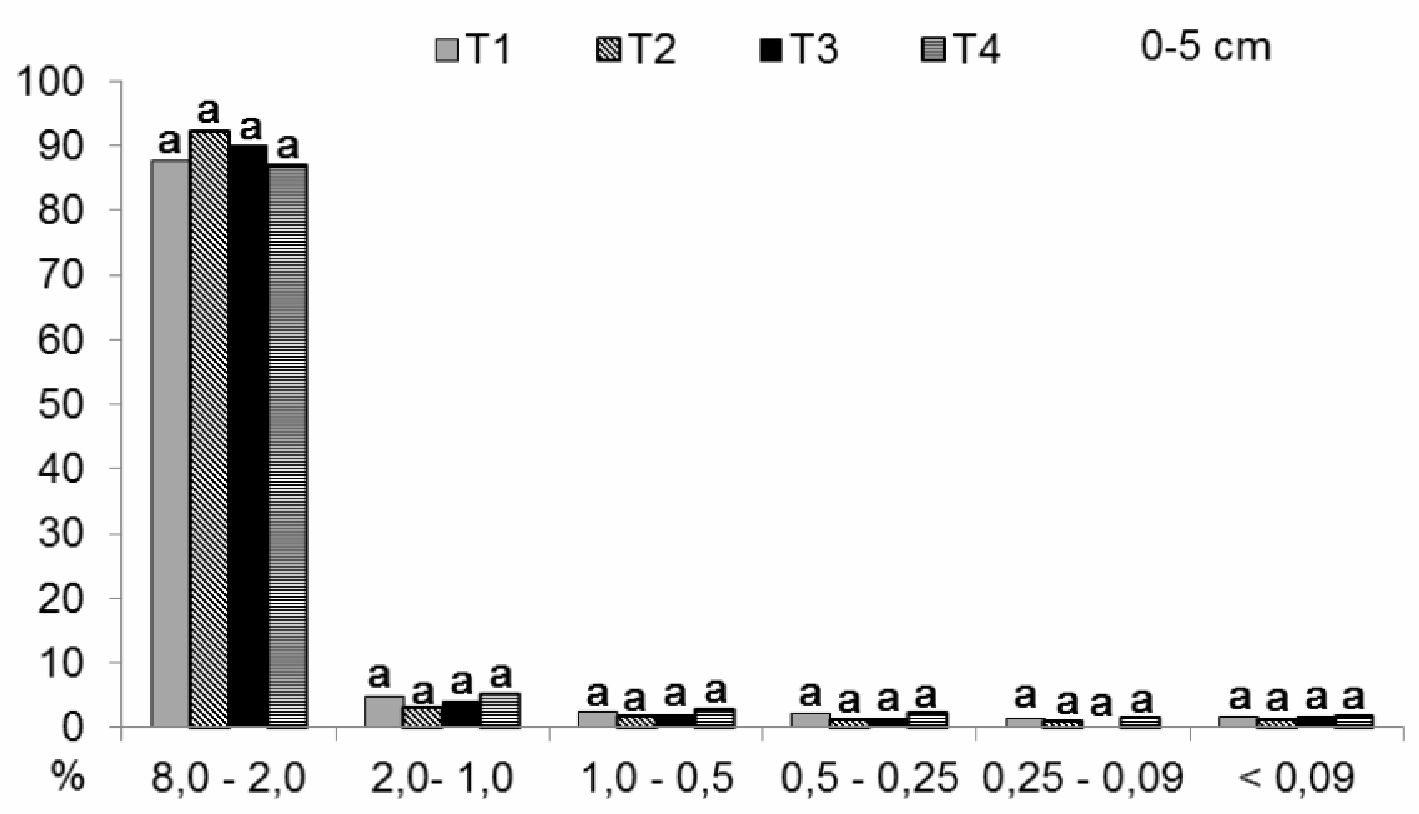

FIGURA 1. Distribuição média de agregados estáveis em água por classes de diâmetro na camada $0-5 \mathrm{~cm}$. $400 \mathrm{Kg} / \mathrm{ha}$ de $\mathrm{N}$ na forma mineral via ureia (T1); $400 \mathrm{Kg} / \mathrm{ha}$ de $\mathrm{N}$ na forma orgânica via esterco bovino (T2); $400 \mathrm{Kg} / \mathrm{ha}$ de N, $50 \%$ na forma mineral e 50\% na forma orgânica (T3) e sem adubação nitrogenada (T4). Médias com letras iguais comparando os tratamentos para cada classe não diferem entre si, pelo teste de Scott-Knott.

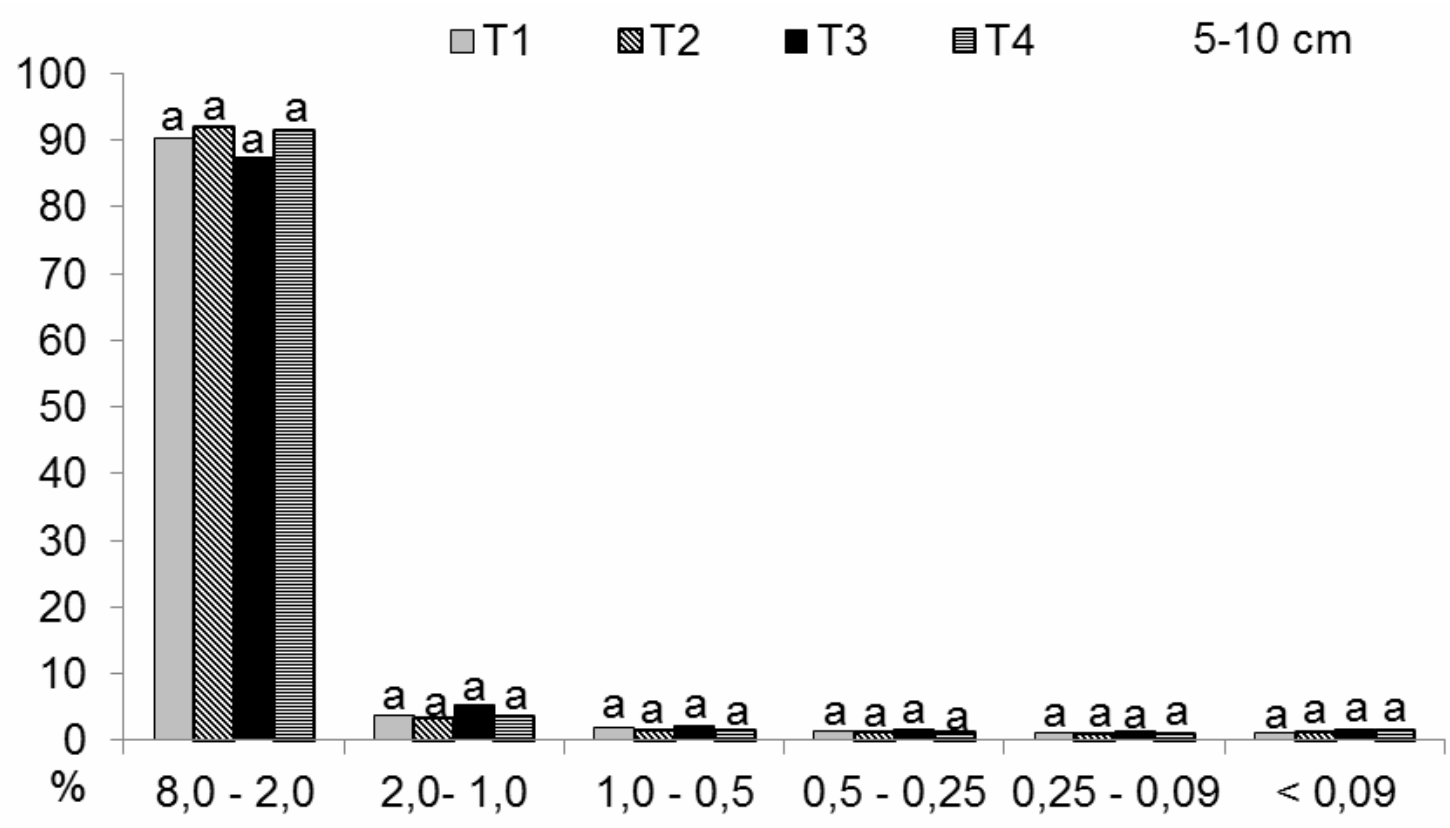

FIGURA 2. Distribuição média de agregados estáveis em água por classes de diâmetro na camada $5-10 \mathrm{~cm}$. $400 \mathrm{Kg} / \mathrm{ha}$ de $\mathrm{N}$ na forma mineral via ureia (T1); $400 \mathrm{Kg} / \mathrm{ha}$ de $\mathrm{N}$ na forma orgânica via esterco bovino (T2); $400 \mathrm{Kg} / \mathrm{ha}$ de N, $50 \%$ na forma mineral e 50\% na forma orgânica (T3) e sem adubação nitrogenada (T4). Médias com letras iguais comparando os tratamentos para cada classe não diferem entre si, pelo teste de Scott-Knott. 
Conforme BATISTA et al. (2013), raízes fibrosas auxiliam na formação dos macroagregados, uma vez que as raízes contribuem com a produção de matéria orgânica recente no solo (LOSS et al., 2011), o que corrobora com os resultados obtidos neste trabalho. Além disso, os bioporos provenientes da decomposição e renovação dessas raízes (LIMA et al., 2012), somados à intensa atividade biológica e ao acúmulo de MOS, implicam boas condições para a agregação das partículas do solo (WENDLING et al., 2012).

Outros fatores importantes no processo de agregação estão substancialmente presentes no solo avaliado, como a fração argila, classificando o solo como argiloso a muito argiloso (o limite entre essas classes corresponde a $60 \%$ de argila no solo), e a matéria orgânica (Tabela 1). Segundo SILVA et al. (2014), a textura do solo influencia na formação e na estabilidade de agregados, sendo que solos com maior teor de argila contribuem para a agregação. VEZZANI \& MIELNICZUK (2011) comentam, ainda, que um maior teor da fração argila favorece a aproximação das partículas do solo, devido à presença de cargas elétricas em maiores quantidades. Em contrapartida, horizontes arenosos dificultam a proteção física da matéria orgânica, afetando negativamente a formação de agregados (SANTOS et al., 2011).

Quanto ao teor de MOS, VEZZANI \& MIELNICZUK (2011) defendem que o uso de gramíneas perenes pode retardar a degradação da matéria orgânica em solos submetidos a manejos conservacionistas, conferindo maior aporte de MOS. Contudo, vale ressaltar que o manejo do solo pode ser determinante para a manutenção ou perda dessa qualidade, mesmo com o uso de espécies com elevada capacidade de estruturação do solo, como o capim tifton-85 (SANTOS et al., 2012; COLUSSI et al., 2014; BORGES et al., 2015).

A predominância de agregados retidos nas peneiras com malhas de maiores aberturas confere uma estimativa dos atributos DMP e DMG (BATISTA et al., 2015). Dessa forma, como esperado, esses parâmetros apresentaram valores elevados e também não diferiram estatisticamente entre os tratamentos, assim como para IEA e IF, nas duas camadas avaliadas (Figuras 3 e 4). Contudo, verificou-se entre os ambientes que o regime irrigado expressou valores estatisticamente superiores aos do ambiente de sequeiro, na camada $5-10 \mathrm{~cm}$, exceto para o atributo IF, que indicou ser menos sensível em relação ao uso de irrigação (Figuras 5 e 6).

Em estudo sobre os atributos físicos de um Latossolo Amarelo caulinítico (LA) e um Latossolo Vermelho-Amarelo oxídico-gibbsítico (LVA) submetidos à compactação, SILVA et al. (2006), observaram que o DMG dos agregados no LVA aumentou com a compactação do solo em função da aplicação de pressões intermediárias (até $120 \mathrm{KPa}$ ). Considerando a relação direta entre umidade do solo e suscetibilidade à compactação (LIMA et al., 2012), é possível que o solo irrigado tenha sido mais compactado pelo efeito do pisoteio animal, o que promoveu a agregação de partículas. Além disso, tendo em vista o período de repouso da pastagem, esses agregados foram se tornando mais estáveis, como demonstrando pelo atributo IEA (Figura 6). 


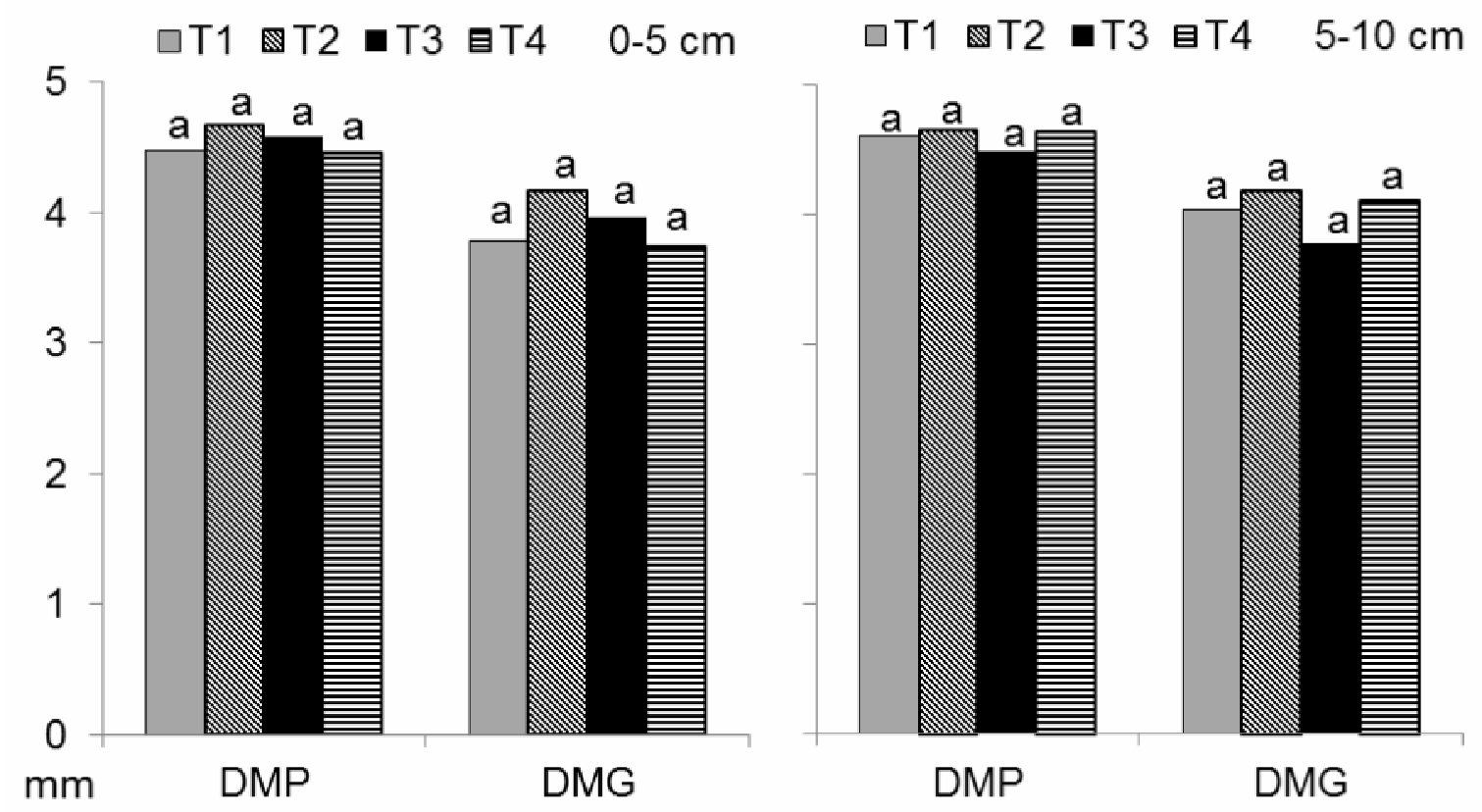

FIGURA 3. Diâmetro médio ponderado (DMP) e diâmetro médio geométrico (DMG) para os tratamentos avaliados nas camadas $0-5$ e $5-10 \mathrm{~cm} .400 \mathrm{Kg} / \mathrm{ha}$ de N na forma mineral via ureia (T1); $400 \mathrm{Kg} / \mathrm{ha}$ de $\mathrm{N}$ na forma orgânica via esterco bovino (T2); $400 \mathrm{Kg} / \mathrm{ha}$ de N, $50 \%$ na forma mineral e $50 \%$ na forma orgânica (T3) e sem adubação nitrogenada (T4). Médias com letras iguais comparando os tratamentos para cada atributo não diferem entre si, pelo teste de Scott-Knott.

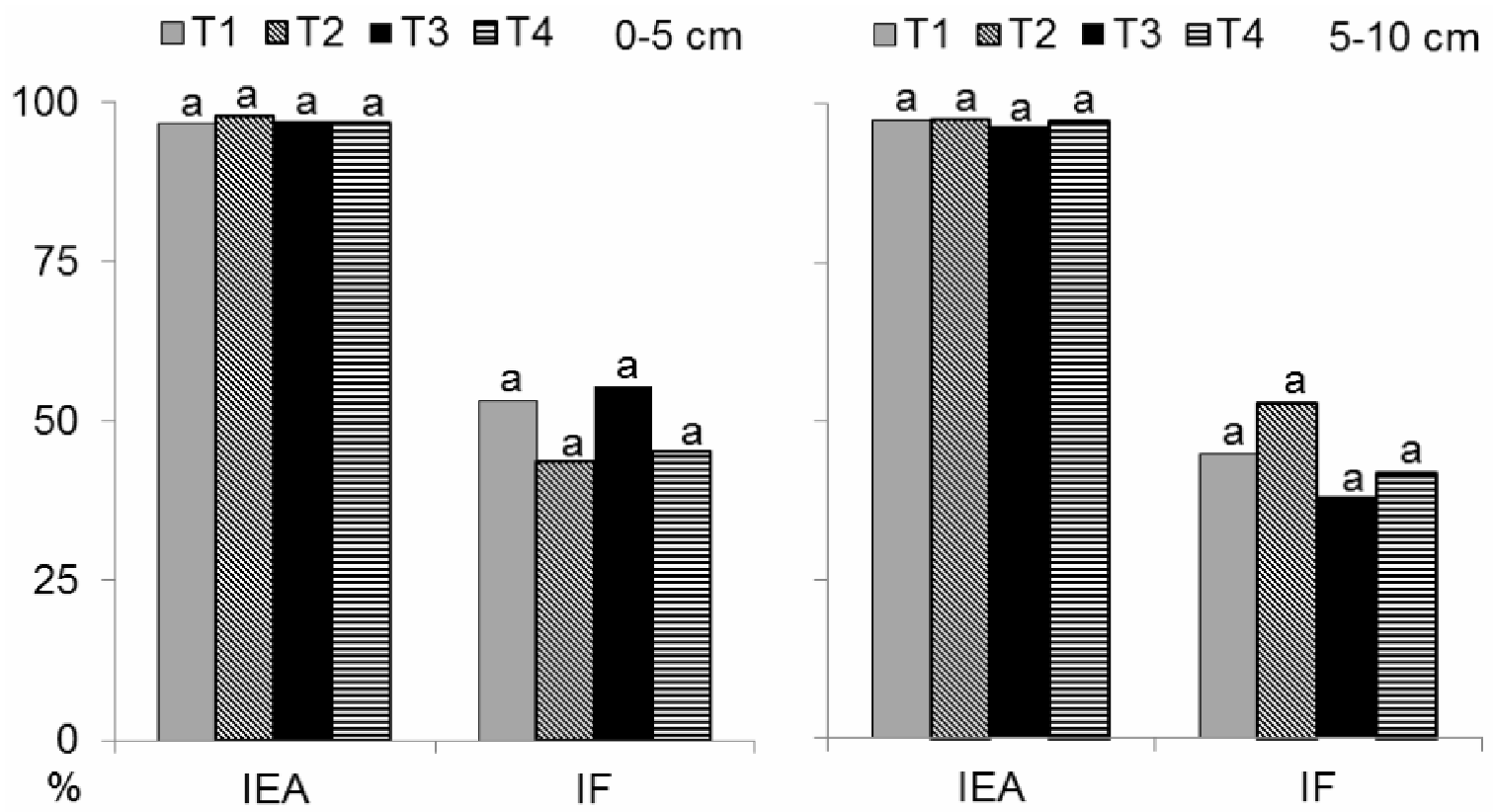

FIGURA 4. Índice de estabilidade de agregados da classe $<0,25 \mathrm{~mm}$ (IEA) e índice de floculação do solo (IF) para os tratamentos avaliados nas camadas 0-5 e 5-10 cm. $400 \mathrm{Kg} / \mathrm{ha}$ de $\mathrm{N}$ na forma mineral via ureia (T1); $400 \mathrm{Kg} / \mathrm{ha}$ de $\mathrm{N}$ na forma orgânica via esterco bovino (T2); $400 \mathrm{Kg} / \mathrm{ha}$ de N, 50\% na forma mineral e $50 \%$ na forma orgânica (T3) e sem adubação nitrogenada (T4). Médias com letras iguais comparando os tratamentos para cada atributo não diferem entre si, pelo teste de Scott-Knott. 


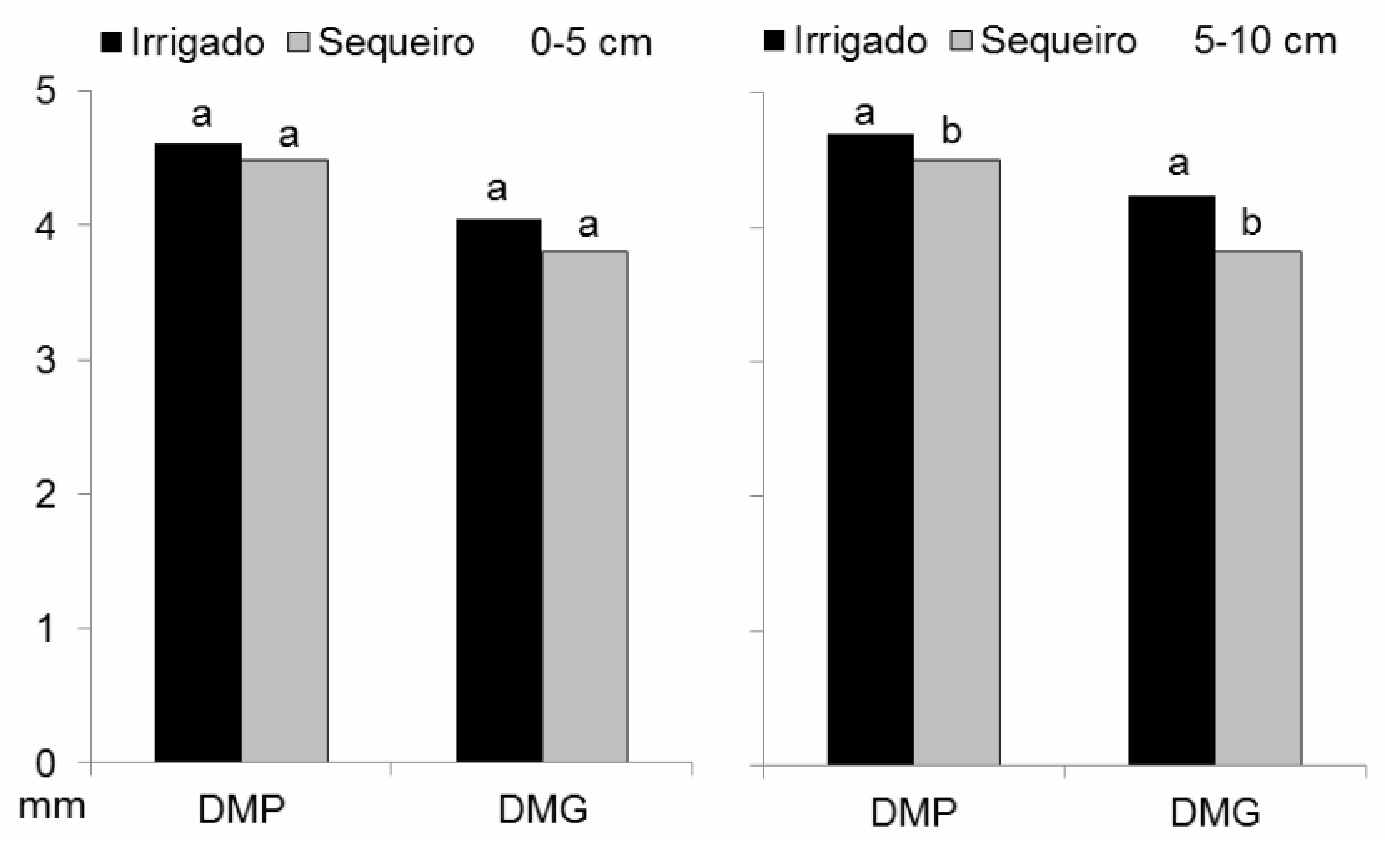

FIGURA 5. Diâmetro médio ponderado (DMP) e diâmetro médio geométrico (DMG) para os ambientes avaliados nas camadas 0-5 e 5-10 cm. Médias com letras iguais comparando os ambientes para cada atributo não diferem entre si, pelo teste de Scott-Knott.

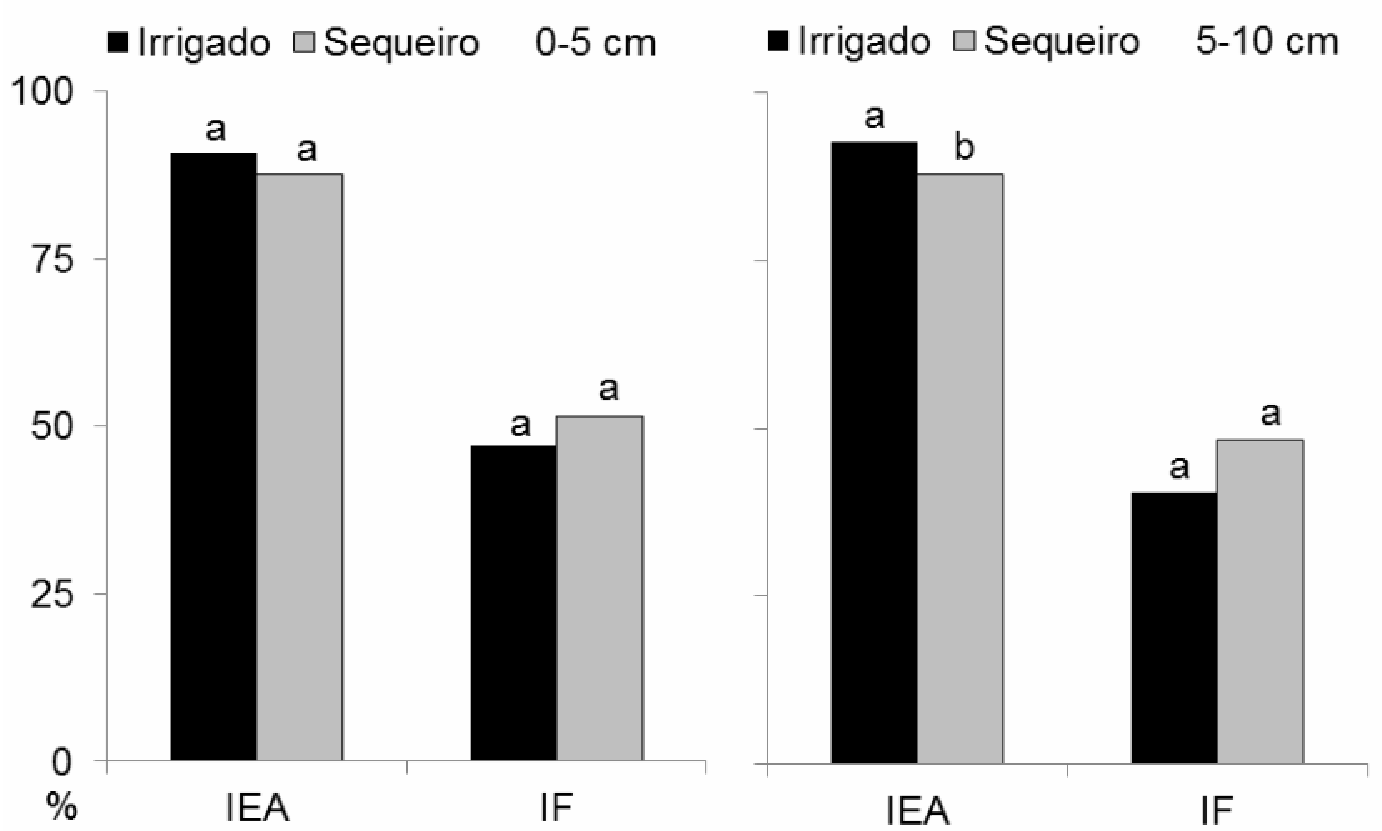

FIGURA 6. Índice de estabilidade de agregados da classe $<0,25 \mathrm{~mm}$ (IEA) e índice de floculação do solo (IF) para os ambientes avaliados nas camadas 05 e 5-10 cm. Médias com letras iguais comparando os ambientes para cada atributo não diferem entre si, pelo teste de Scott-Knott.

Os valores de DMP, DMG, IEA e IF obtidos neste estudo são consideravelmente elevados em comparação aos verificados em trabalhos semelhantes (WENDLING et al., 2005; SANTOS et al, 2012; BATISTA et al., 2015), com destaque para os resultados de WENDLING et al. (2005), os quais avaliaram 
propriedades de agregação do solo em um Latossolo Vermelho cultivado com a mesma espécie forrageira. Os autores determinaram os valores de $2,13 \mathrm{~mm}$ para DMP e 1,44 mm para DMG na camada $0-5 \mathrm{~cm}$, e 2,09 mm para DMP e 1,48 mm para DMG na camada $5-10 \mathrm{~cm}$. Em relação ao IEA, as médias das camadas foram equivalentes a $76,13 \%(0-5 \mathrm{~cm})$ e $84,83 \%(5-10 \mathrm{~cm})$. Segundo REIS et al. (2014), a exsudação de compostos radiculares, a microfauna rizosférica e a ação mecânica de penetrabilidade do sistema radicular no solo são os fatores que explicam a elevação dos parâmetros de agregação.

Dessa forma, esses resultados podem ser atribuídos ao elevado aporte de matéria orgânica no solo, além da alta densidade e taxa de renovação de raízes do capim-tifton 85, associada ao período de repouso da pastagem, o que, por sua vez, favorece o acúmulo de exsudados radiculares e de matéria orgânica proveniente de raízes em decomposição. Esses fatores, por sua vez, implicam estímulo à ação de micro-organismos, os quais secretam compostos que também atuam como agentes cimentantes das partículas do solo (CASTRO FILHO et al., 1998). Todos esses processos são, em última análise, viabilizados pela textura argilosa a muito argilosa do Latossolo em estudo, através da ação protetiva da matéria orgânica realizada pelas argilas (SANTOS et al., 2011), além do próprio efeito cimentante dos óxidos de ferro e alumínio presentes em Latossolos muito intemperizados, como o de presente estudo (FERREIRA et al., 1999).

\section{CONCLUSÃO}

O uso da irrigação em Latossolo Vermelho distrófico argiloso sob capim-tifton 85 favorece a estabilidade da estrutura do solo. Em contrapartida, a forma de suprimento de $\mathrm{N}$ para adubação dessa forrageira indica ser pouco determinante para alterações significativas nos atributos físicos avaliados, com aplicação por aproximadamente dois anos.

\section{AGRADECIMENTOS}

À UFSJ, À EPAMIG ao CNPq pelos recursos disponibilizados para a realização deste trabalho.

\section{REFERÊNCIAS}

BASSO, C. J.; PIAS, O. H. C.; SANTI, A. L.; BIER, D. R.; PINTO, M. A. B. Variabilidade da produção do Tifton 85 e sua correlação com os atributos físicos do solo. Brazilian Journal of Agricultural Sciences/Revista Brasileira de Ciências Agrárias, v. 9, n. 4, 2014. Disponível em: <http://www.agraria.pro.br/sistema/ index.php?journal=agraria\&page=article\&op=view\&path\%5B\%5D=agraria_v9i4a439 5\&path\%5B\%5D=1686>. doi: 10.5039/agraria.v9i4a4395

BATISTA, A. M.; PRETO, V. R. O.; CAMPOS, M. P.; SILVA, B. M.; CAIXETA, S. P. Efeito da adubação verde na estabilidade de agregados de um solo sob cultivo de hortaliças orgânicas na região de Capim Branco - MG. Enciclopédia Biosfera, Centro Científico Conhecer - Goiânia, v.11 n.22; p. 2015. Disponível em: <http://dx.doi.org/10.18677/Enciclopedia_Biosfera_2015_141>. doi: 10.18677/ Enciclopedia_Biosfera_2015_141

BATISTA, I.; CORREIA, M. E. F.; PEREIRA, M. G.; BIELUCZYK, W.; SCHIAVO, J. A.; MELLO, N. A. Caracterização dos agregados em solos sob cultivo no Cerrado, MS. Semina: Ciências Agrárias, Londrina, v. 34, n. 4, p. 1535-1548,2013. 
Disponível em: <http://www.uel.br/revistas/uel/index.php/semagrarias/article/view/ 10613/13106>. doi: 10.5433/1679-0359.2013v34n4p1535

BORGES, C. S.; RIBEIRO, B. T.; WENDLING, B.; CABRAL, D. A. Agregação do solo, carbono orgânico e emissão de $\mathrm{CO}_{2}$ em áreas sob diferentes usos no Cerrado, região do Triângulo Mineiro. Revista Ambiente \& Água, Taubaté, v.10, n.3, 2015. Disponível em: <http://dx.doi.org/10.4136/ambi-agua.1573>. doi: 10.4136/ambiagua. 1573

CALONEGO, J. C.; ROSOLEM, C. A. Estabilidade de agregados do solo após manejo com rotações de culturas e escarificação. Revista Brasileira de Ciência do Solo, v. 32, n. 04, p.1399-1407, 2008. Disponível em: <http://dx.doi.org/ 10.1590/S0100-06832008000400004>. doi: 10.1590/S0100-06832008000400004

CASTRO FILHO, C.; MUZILLI, O.; PODANOSCHI, A. L. Estabilidade dos agregados e sua relação com o teor de carbono orgânico num Latossolo Roxo distrófico, em função de sistema de plantio, rotações de culturas e métodos de preparo das amostras. Revista Brasileira de Ciência do Solo, Viçosa, v.22, n.3, p.527-38, 1998. Disponível em: <http://dx.doi.org/10.1590/S0100-06831998000300019>. doi: 10.1590/S0100-06831998000300019

COLUSSI, G; SILVA, L. S.; MINATO, E. A. Escarificação e adubação orgânica: efeito na recuperação estrutural de solo produzindo Tifton 85. Ciência Rural, Santa Maria, v.44, n.11, p.1956-1961, nov, 2014. Disponível em: <http://dx.doi. org/10.1590/01038478cr20131670>. doi: 10.1590/0103-8478cr20131670

EMBRAPA. Manual de Métodos de Análise de Solo. 2. ed. Rio de Janeiro - RJ: Documento 182, Embrapa Solos, Centro Nacional de Pesquisa de Solos. Embrapa Produção de Informação, 2011.

EMBRAPA. Pastagens no Cerrado: Baixa Produtividade pelo Uso Limitado de Fertilizantes. 1. ed. Planaltina - DF: Documento 50, Embrapa Cerrados, 2002. 32 p.

EMBRAPA. Sistema Brasileiro de Classificação de Solos. 3 ed. Brasília, DF: Embrapa Solos, 353 p. 2013.

FERREIRA, E. B.; CAVALCANTI, P. P.; NOGUEIRA, D. A. ExpDes: an R package for ANOVA and experimental designs. Applied Mathematics, Alfenas, v. 5, n. 19, p. 2952, 2014. Disponível em: <http://www.scirp.org/journal/Paperlnformation.aspx? Pape ID=51204 >. doi: 10.4236/am.2014.519280

FERREIRA, M. M.; FERNANDES, B.; CURI, N. Influência da mineralogia da fração argila nas propriedades físicas de Latossolos da região sudeste do Brasil. Revista Brasileira de Ciência do Solo, v. 23, n. 3, p. 515-524, 1999. Disponível em: <http://dx.doi.org/10.1590/S0100-06831999000300004>. doi: 10.1590/S0100-06831 999000300004

FIDALSKI, J. Qualidade física de Latossolo Vermelho em sistema de integração lavoura-pecuária após cultivo de soja e pastejo em braquiária. Pesquisa agropecuária brasileira, Brasília, v. 50, n. 11, p.1097-1104, 2015. Disponível em: <http://dx.doi.org/10.1590/S0100-204X2015001100013>. doi: 10.1590/S0100-204X2 015001100013 
FIDALSKI, J.; TORMENA, C.A.; ALVES, S.J. Intervalo hídrico ótimo de um Latossolo Vermelho distrófico, após o primeiro período de pastejo contínuo de Brachiaria ruziziensis, em sistema integração lavoura-pecuária. Revista Brasileira de Ciência do Solo, v.37, p.775-783, 2013. Disponível em: <http://dx.doi.org/10.1590/S010006832013000300024>. doi: 10.1590/S0100-06832013000300024

IBGE. Minas Gerais, Prudente de Morais, infográficos: histórico. IBGE Cidades, 2013. Disponível em: <http://ibge.gov.br/cidadesat/painel/historico.php?lang= \&codmun=315360\&search=minasgeras|prudente-de-morais|infograficos:-historico $>$. Acesso em 20 de dezembro. 2016.

LIMA, V. M. P.; OLIVEIRA, G. C.; SERAFIM, M. E.; CURI, N.; EVANGELISTA, A. R. Intervalo hídrico ótimo como indicador de melhoria da qualidade estrutural de Latossolo degradado. Revista Brasileira de Ciência do Solo, v. 36, p.71-78, 2012. Disponível em: <http://dx.doi.org/10.1590/S0100-06832012000100008>. doi: 10.1590/S0100-06832012000100008

LOSS, A.; PEREIRA, M. G.; GIÁCOMO, S. G.; PERIN, A.; ANJOS, L. H. C. Agregação, carbono e nitrogênio em agregados do solo sob plantio direto com integração lavoura-pecuária. Pesquisa Agropecuária Brasileira, v. 46, n. 10, p. 1269-1276, 2011. Disponível em: <http://dx.doi.org/10.1590/S0100-204X2011001000 022>. doi: 10.1590/S0100-204X2011001000 022

MAPCOORDINATES. Disponível em: <http://www.mapcoordinates.net/pt>. Acesso em 26 de dezembro. 2016.

OLIVEIRA, D. M. S.; LIMA, R. P.; JAN VERBURG, E. E. Qualidade física do solo sob diferentes sistemas de manejo e aplicação de dejeto líquido suíno. Revista Brasileira de Engenharia Agrícola e Ambiental, v. 19, n. 3, p. 280-285, 2015. Disponível em: <http://dx.doi.org/10.1590/1807-1929/agriambi.v19n3p280-285>. doi: 10.1590/1807-1929/agriambi.v19n3p280-285

ORTIGARA, C.; KOPPE, E.; LUZ, F. B; BERTOLLO, A. M.; KAISER, D. R.; SILVA, V. R. Uso do solo e propriedades físico-mecânicas de Latossolo Vermelho. Revista Brasileira de Ciência do Solo, v. 38, n. 2, p. 619-626, 2014. Disponível em: <http://dx.doi.org/10.1590/S0100-06832014000200026>. doi: 10.1590/S0100-06832 014000200026

PERON, A. J.; EVANGELISTA, A. R. Degradação de pastagens em regiões de cerrado. Ciência e Agrotecnologia, Lavras, v. 28, n. 3, p. 655-661, 2004. Disponível em: <http://dx.doi.org/10.1590/S1413-70542004000300023>. doi: 10.1590/S141370542004000300023

REIS, D. A.; LIMA, C. L. R.; PAULETTO, E. A. Resistência tênsil de agregados e compressibilidade de um solo construído com plantas de cobertura em área de mineração de carvão em candiota, RS. Revista Brasileira de Ciência do Solo, v.38 n.2, p. 669-678, 2014. Disponível em: <http://dx.doi.org/10.1590/S010006832014000200031 >. doi: 10.1590/S0100-06832014000200031

RESENDE, T. M.; MORAES, E. R.; FRANCO, F. O.; ARRUDA, E. M.; ARAÚJO, J. R.; SANTOS, D. S.; BORGES, E. N.; RIBEIRO, B. T. Avaliação física do solo em áreas sob diferentes usos com adição de dejetos animais no bioma Cerrado. 
Bioscience Journal, Uberlândia, v. 28, p. 179-184, 2012. Disponível em: <http: //www.seer.ufu.br/index.php/biosciencejournal/article/view/13320/8361>.

SANCHES, A. C.; GOMES, E. P.; RICKLI, M. E.; FASOLIN, J. P.; SOARES, M. R. C.; GOES, R. H. T. B. Produtividade e valor nutritivo do capim Tifton 85 irrigado e sobressemeado com aveia. Revista Brasileira de Engenharia Agrícola e Ambiental, v. 19, n. 2, p. 126-133, 2015. Disponível em: <http://dx.doi.org/10.1590/ 1807-1929/agriambi.v19n2p126-133>. doi: 10.1590/1807-1929/agriambi.v19n2p126133

SANTOS, D. C.; PILLON, C. N.; FLORES, C. A.; LIMA, C. L. R.; CARDOSO, E. M. C.; PEREIRA, B. F.; MANGRICH, A. F. Agregação e frações físicas da matéria orgânica de um Argissolo Vermelho sob sistemas de uso no bioma Pampa. Revista Brasileira de Ciência do Solo, v. 35, p. 1735-1744, 2011. Disponível em: <http://www.scielo.br/scielo.php?pid=S010006832011000500028\&script=Sci_arttext >. doi: 10.1590/ S0100-06832011000500028.

SANTOS, D. S.; ARRUDA, E. M.; MORAES, E. R.; FRANCO, F. O.; ARAÚJO, J. R.; RESENDE, T. M.; BORGES, E. N.; RIBEIRO, B. T. Atributos físicos e Matéria orgânica de áreas de Latossolo utilizadas para atividade pecuária no bioma Cerrado. Bioscience Journal, Uberlândia, v. 28, n. 4, p. 500-508, 2012. Disponível em: < http://www.seer.ufu.br/index.php/biosciencejournal/article/view/13287/9739>.

SEVERIANO, E. C.; OLIVEIRA, G. C.; DIAS JUNIOR, M. S.; COSTA, K. A. P.; CASTRO; M. B.; MAGALHÃES, E. N. Potencial de descompactação de um Argissolo promovido pelo capim-tifton 85. Revista Brasileira de Engenharia Agrícola e Ambiental, v.14, n.1, p.39-45, 2010. Disponível em: <http://dx.doi.org/10.1590/ S1415-43662010000100006 >. doi: 10.1590/S1415-43662010000100006

SILVA, A. S; SILVA, I. D. F.; BANDEIRA; L. B., DIAS, B. O.; SILVA NETO, L. D. F. Argila e matéria orgânica e seus efeitos na agregação em diferentes usos do solo. Ciencia rural, v. 44, n. 10, p. 1783-1789, 2014. Disponível em: <http://dx.doi.org/ 10.1590/0103-8478cr20130789 >. doi: 10.1590/0103-8478cr2013078

SILVA, S. R.; BARROS, N. F.; COSTA, L. M. Atributos físicos de dois Latossolos afetados pela compactação do solo. Revista Brasileira de Engenharia Agrícola e Ambiental, v. 10, p. 842-847, 2006. Disponível em: <http://dx.doi.org/10.1590/S1415 -43662006000400009>. doi: 10.1590/S1415-43662006000400009

VEZZANI, F. M.; MIELNICZUK, J. Agregação e estoque de carbono em Argissolo submetido a diferentes práticas de manejo agrícola. Revista Brasileira de Ciência do Solo, v. 35, p. 213-223, 2011. Disponível em: <http://www.scielo.br/scielo.php? pid=S010006832011000100020\&script=sci_arttext $>$. doi: 10.1590/S0100-06832011 000100020.

WALKLEY, A.; BLACK, I. A. An examination of the Degtjareff method for determining soil organic matter and a proposed modification of the chromic acid titration method. Soil Science, Baltimore, v.37, n.1, p.29-38, jan./jun. 1934. Disponível em: <http://journals.Iww.com/soilsci/Citation/1934/01000/AN_EXAMINATION_OF_THE_ DEGTJAREFF_METHOD_FOR.3.aspx>. 
WENDLING, B.; JUCKSCH, I.; MENDONÇA, E. S.; NEVES, J. C. L. Carbono orgânico e estabilidade de agregados de um Latossolo Vermelho sob diferentes manejos. Pesquisa agropecuária brasileira, Brasília, v.40, n.5, p.487-494, 2005. Disponível em: <http://dx.doi.org/10.1590/S0100-204X2005000500010>. doi: 10.1590/S0100-204X2005000500010

WENDLING, B.; VINHAL-FREITAS, I. C.; OLIVEIRA, R. C.; BABATA, M. M.; BORGES, E. N. Densidade, agregação e porosidade do solo em áreas de conversão do cerrado em floresta de pinus, pastagem e plantio direto. Bioscience Journal, v. 28, p. 256-265, 2012. Disponível em: < http://www.seer.ufu.br/index.php/bioscience journal/article/view/13277/8371>. 